\title{
RANGKAIAN ANTI MALING SISTEM KEAMANAN KONTAK RAHASIA PADA SEPEDA MOTOR
}

\author{
SECRET CONTACT SECURITY SYSTEM ANTI THEM CIRCUITS ON MOTORCYCLES \\ Firnanda Faiq Iswanto ${ }^{1}$, Ilham Maulana ${ }^{2}$,Haris Wibisono ${ }^{3}$, Bintang Yudhistira Adi wibowo ${ }^{4}$. \\ ${ }^{1}$ (Teknik Mesin, Universitas Muhammadiyah Jember) Email: faiqstyles@gmail.com \\ 22(Teknik Mesin, Muhammadiyah Jember) Email: im2531233@gamil.com \\ ${ }^{3}$ (Teknik Mesin, Universitas Muhammadiyah Jember) Email: hariswibisono9@gmail.com \\ ${ }^{4}$ (Teknik Mesin, Univeritas Muhammadiyah Jember) Email: bintangyudhistira01@ gmail.com
}

\begin{abstract}
A.TUJUAN
1.Mahasiswa dapat membuat system keamanan pada sepeda motor alat anti maling.

2.Mahasiswa mampu menganalisis system kerja keamanan sepedah motor.

LANDASAN TEORI

Kemajuan ilmu pengetahuan dan teknologi saat ini terus berkembang pesat seiring dengan permasalahan yang terus bermunculan dan semakin komplek pada berbagai bidang kehidupan, termasuk dalam bidang transportasi.pada kali ini kami akan membuat salah satu teknologi tentang system keamanan sepeda motor.[1]

Di Indonesia kebutuhan alat transportasi yang praktis dan memiliki keunggulan baik untuk kerja mesin maupun teknologi yang diterapkannya sangat diminati masyarakat. Tetapi dalam segi keamanan kurang di karenakan bayaknya tingkat criminal di Indonesia, salah satunya pencurian kendaran yang membuat masyarakat harus lebih waspada.[2]

Beberapa anggota komunitas sepeda motor sangat senang memodifikasi sepeda motornya, mulai dari body, mesin, pengapian, pembakaran sampai sistem pengereman.Bahkan juga ada modifikasi dalam keamanan sepeda motor utuk menjaga tingkat keamanan agar saat sepeda motor kita tinggal pergi maka aka aman.meskipun saat ini pembuatan sepeda motor sudah di beri keamanan dari pabriknya masih belum menjamin tingkat keamanannya.[3]

Salah satu cara yang dapat dilakukan oleh perusahaan agar konsumen puas dan akhirnya loyal adalah memberikan augmented product (produk tambahan), yaitu berbagai atribut produk yang dilengkapi atau ditambahkan berbagai manfaat sehingga memberikan tambahan kepuasan dan mampu dibedakan dengan produk pesaing. Salah satu produk yang kami buat kali ini yaitu alat keamanan kunci rahasia dalam sebuah sepeda motor agar terhindar dari pencurian. [4]

Kami juga sudah membuat sebuah rancangan untuk alat keamanan sepeda motor bawasannya agar pembaca artiker ini tau bagaimana system alat ini dan bisa di terapkan juga. Pembuatan alat ini ditunjukan pada bentuk flowchart pada Gambar 1.
\end{abstract}




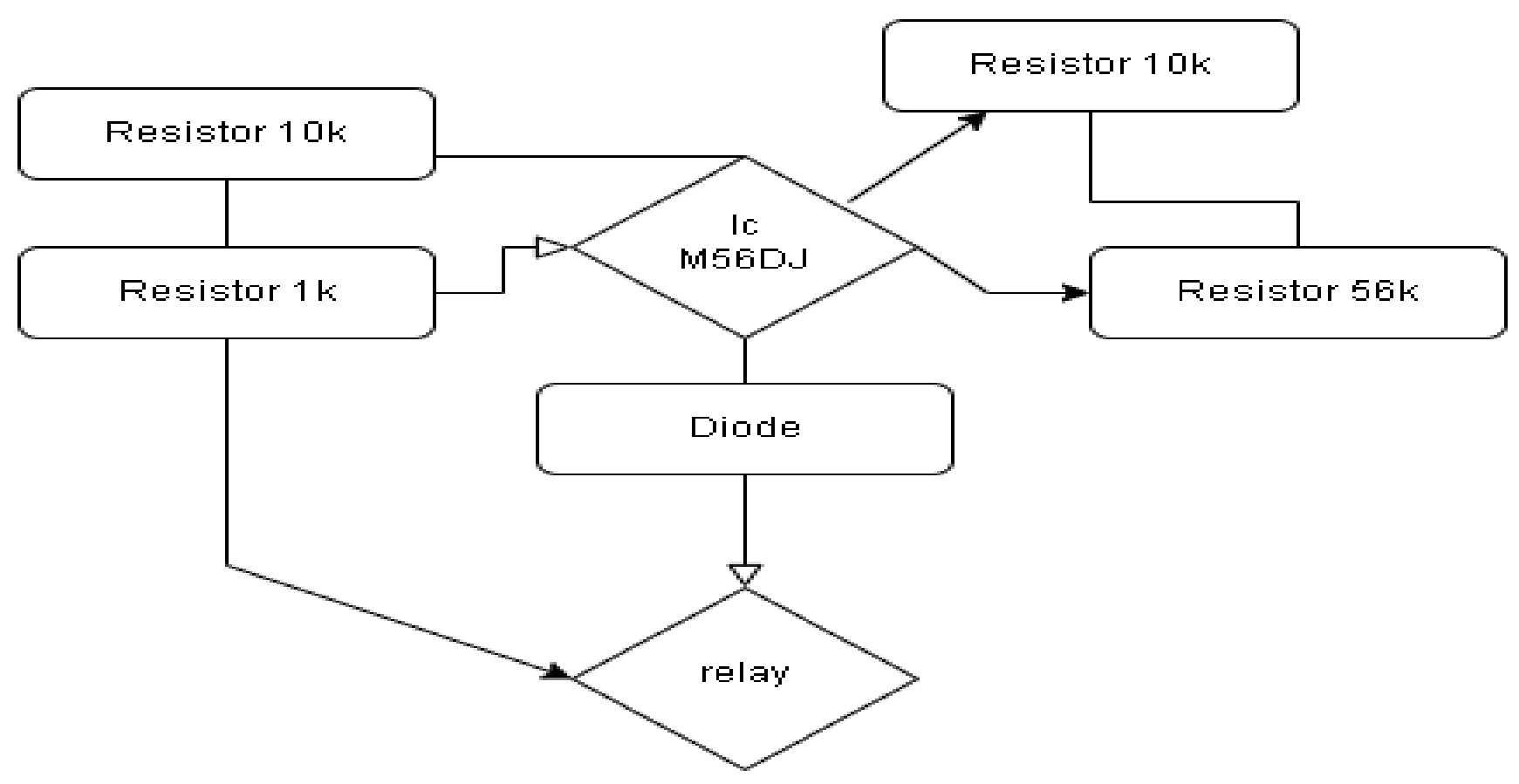

Gambar 1.Sistem Alat Anti Maling

Pada diagram blok diagram menjelaskan desain sistem keseluruhan pada alat. System terdiri dari beberapa komponen yaitu RELA, IC,RESISTOR,TRANSISTOR,DIODE,KABEL,Dan PCB.[4]Kenapa kamu menggunakan bodi sepeda motor sebagai kunci rahasia dikarenakan yaitu agar lebih simple dan menarik. Bodi kendaraan merupakan bagian terluar yang memberi aspek keindahan guna menjadi daya tarik bagi konsumen.[6]

\section{ALAT DAN BAHAN}

\section{Relay 12v A1}

Relay merupakan bentuk hambatan terdiri atas titik-titik kontak bawah dengan gulungan spool-nya tidak bergerak dan titik kontak bagian atas yang bergerak. Prinsip kerja hambatan adalah menghubungkan titik-titik kontak bagian bawah dengan titik bagian atas yaitu terletak gulungan spool dialiri arus listrik yang timbul elektromagnet. Pembuatan alat ini menggunakan jenis Relay 12v Ai yang berfungsi untuk menghubungkan aliran listrik system otomatis dalam alat anti maling.[7]

\section{Ic NE55}

pemilihan ic dilakukan berdasarkan spesifikasi yang dimiliki ic tersebut dan dapat digunakan sebagai penguat dengan dual supply Input. Ic dalam alat ini berfungsi untukmengatur aliran listrik yang di butuhkan system otomatis.[8]

\section{Resistor 1k}

Resistor adalah komponen elektronika yang berfungsi untuk membagi tegangan atau menghambat arus listrik. Resistor ini untuk menstabilkan aliran listrik yg berlebihan pada alat ini.[9]

\section{Resistor56k}

resistor R11 bernilai 56K dapat berfungsi sebagai low pass filter orde satu untuk meredam sinyal diatas $100 \mathrm{~Hz}$. Kegunaan 56k ini juga sama dengan resistor 1k.[10]

\section{Resistor 10k}


Resistor sebesar 10K ohm pada setiap sambungan antara kabel jumper dengan sensor flex. Memiliki kegunaan yang sama juga dengan resistor $1 \mathrm{k}$ dan 56k.kesimpulannya tanpa resistor maka aliran listrik lebih los atau lebih tepatnya tidak beraturan.[11]

\section{Transistor PNP}

Transistor jenis PNP, yang dianggap sebagai anoda ialah tep/kaki basis. Bertujuan agar alat ini bisa teratur aliran listriknya fungsinya hapir sama dengan diode SCR.

\section{Diode 1 Amper}

Karakter diode secara umum memiliki tegangan dadal cukup besar ( $>50$ volt) sehingga sumber tegangan yang menghasilkan nilai beda tegangan $>50$ volt agak sulit diperoleh. Berguna untuk menarahkan aliran listrik bolak-balik menjadi searah.[12]

\section{Kabel}

Setiap kabel mempunyai kemampuan dan spesifikasi yang berbeda. Kabel ini pada alat anti maling guna untuk menghubungkan aliran listrik ke batrai(+ -).

\section{PCB Manufakturin}

PCB merupakan singkatan dari Printed Circuit Board yang diartikan dalam bahas Indonesia yaitu papan rangkaian atau papan sirkuit cetak. Seperti terjemahannya, PCB adalah papan yang digunakan untuk menghubungkan komponenkomponen elektronika dengan lapisan jalur konduktornya. PCB ini dalam alat ini guna untuk menepatkan satuan komponen yang ada di alat anti maling ini.[13]

\section{PROSEDUR}

Pemasangan alat ke sepeda motor:

1. Tahap awal taruh alat keamanan sepeda motor ke tempat yang sekiranya ada ruang bisa di bawah tangki atau body sepedah motor.

2. Kabel positif merah satukan ke kabel warna coklat untuk Yamaha sedangkan untuk honda hitam pada jalur suwit rem warna hitam atau coclat atau relay pada fleser listing.

3. Arus batrrai positif pada massa body menghubungkan ke kontak pengapian pulser positif.

4. Lalu jalur anten di hubungkan ke body plastic yang di inginkan.

5. Setelah selesai pemasangan alat on kan kontak lalu sentuh jalur anten ke body atau kover plastic untuk menggerakkan aliran listrik pada relay.

6. Stater sepeda dan on apabila body yang terdapat jalur anten tidak di sentuh maka sepeda motor tidak menyala.

Proses sistem kerja alat ini terdapat pada bentuk flowchart pada Gambar 2. 


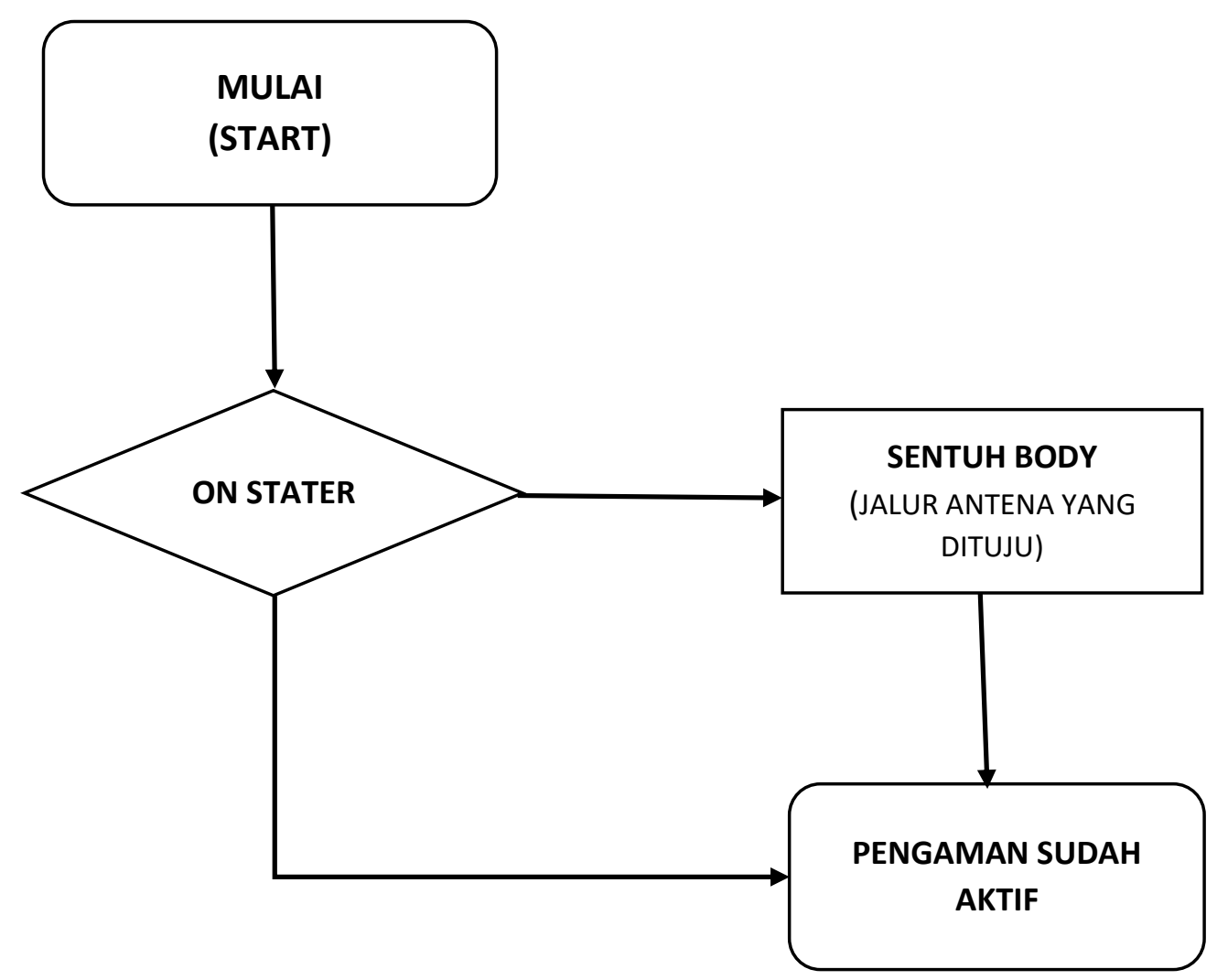

Gamba 2 .Sistem Kerja Alat Anti Maling

\section{HASIL}

Pembuatan alat ini cukup simple dan bisa di jual belikan di pasaran di karenakan cara pemasangan yang mudah karena tahapan yang kami buat tidak terlalu Panjang atau memakan waktu yang banyak. Alat keamana anti maling sepeda motor ini memiliki ukuran yang kecil jadi saat pemasangan di sepeda motor tidak memakan ruang. Salahsatu alat keamanan anti maling yang sudah jadi pada Gambar 3 dan 4 berikut.

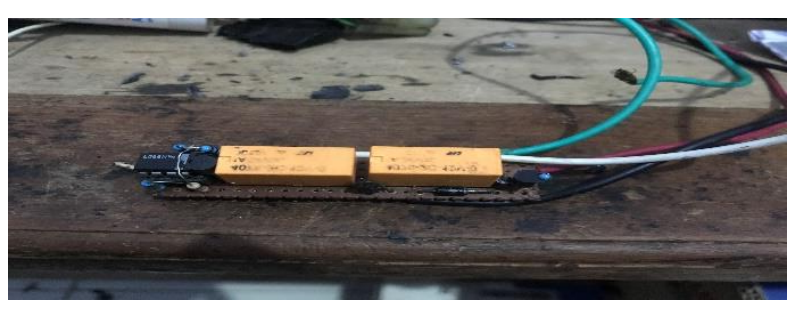

Gambar 3. bagaian dalam alat anti maling.

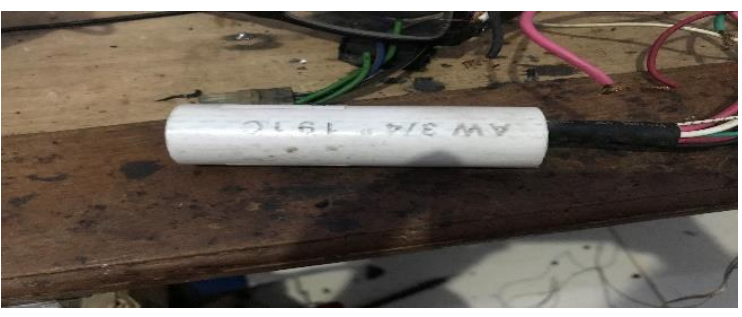

Gambar 4. Bagian luar alat anti maling siap pasang

Alat anti maling ini hanya memiliki satu fitur yaitu touch the body agar kendaran bisa menyala. Sebenarnya masih bisa di tambah fitur lain seperti auto on sirine pada jarak beberapa meter, tetapi di sini kami hanya membuat alat anti maling yang hanya memiliki 1 fitur saja. Mungkin kedepanya kami akan mengembangkan lagi alat ini di karenakan masih terdapat kekurangan salah satunya pemakaian kurang tahan lama kendala pada Ic yang kurang cocok. 


\section{KESIMPULAN}

Hasil dari alat ini berpengaruh penting bawasannya jika kendaraan sepeda motor yang memiliki keamanan yang kurang maka sangat beresiko bagi pemilik sepeda motor tersebut. Banyaknya kasus pencurian saat ini membuat masyarakat gelisah karena takut jika kendaraan mereka di curi. Maka dari itu kami membuat sebuah alat keamanan anti maling yang bisa meningkatkan keamanan pada sepeda motor. Semoga alat ini bisa bermanfaat dalam membantu masyarakat kedepanya dan alat ini bisa lebih dikembangkan lagi.

\section{DAFTAR PUSTAKA}

[1] I. Tri Wahyulianto Putra et al., "PERBANDINGAN CDI STANDAR DAN CDI VARIASI TERHADAP PERFORMA MOTOR 4 TAK 100 CC COMPARISON STANDARD CDI AND VARIATIONS TO MOTORCYCLE PERFORMANCE 4 TAK 100 CC," 2018.

[2] N. Ana Mufarida, A. Fathoniyam Putra Nusantara, and J. Teknik Mesin, "PENGARUH MODIFIKASI LIFT CAMSHAFT TERHADAP PERFORMA MOTOR 4 TAK 100CC The Effect of Camshaft Lift Modification on the Performance of 100cc Motorbike," 2017.

[3] M. A. P. Anggraista A, "ANALISIS KEKUATAN MATERIAN BAJA S45C PADA PERENCANAAN ARM DAN POROS PENYANGGA DISC BRAKE BELAKANG MOTOR SKUTER 2 TAK 150CC,” vol. 3, no. 1, pp. 1-4, 2018.

[4] T. Palupi, R. Institut, T. Dan, B. Widya, and G. Lumajang, "Implementasi Strategi Augmented Product Dan Atribut Produk Sepeda Motor Merek Honda Dalam Menciptakan Kepuasan Konsumen.” [Online]. Available: https://kumparan.com/kumparanoto/honda-kuasai-75-persen-

[5] M. A. Auliq and R. Zamroni, "Prototype Alat Pendeteksi Dini Gangguan Fuse Cut Out (FCO) Sistem Kelistrikan PLN Berbasis IoT," 2021, doi: 10.32528/elkom.v3i2.5569.

[6] D. Adi Tyagita, A. Wahyu Pratama, D. Bagus Aprianto, P. Studi Mesin Otomotif, J. Teknik, and P. Negeri Jember, "Variation Of Tinner Level And Drying Temperature On Quality of ABS Vehicle Bodies Painting," 2019.

[7] P. Studi Teknik Elektronika Laporan Tugas Akhir, "Politeknik Negeri Sriwijaya." [Online]. Available: http://teknikelektronika.com/pengertian-baterai-jenis-jenis-baterai/

[8] M. Agustini, S. Oktaviani, F. Muhammad, and D. E. Mozef, "Perancangan dan Realisasi Sistem Komunikasi Suara dengan Penjelasan Suara yang Ditransmisikan dari Cahaya Lampu Penerangan LED."

[9] P. Hayati, "RANCANG BANGUN KEAMANAN BERANGKAS PENYIMPANAN DENGAN MENGGUNAKAN FACE ID BERBASIS RASPBRRY PI 3.”

[10] M. N. Robby and R. Effendie, "PERANCANGAN SIMULATOR GERAK DAN SISTEM MONITORING UNTUK MENGGERAKKAN DAN MEMONITORING TANGAN PALSU ELEKTRIK”.

[11] J. Chandra and A. Arifin, "RANCANG BANGUN SISTEM EEG UNTUK MENGIDENTIFIKASI GERAKAN PADA UPPER LIMB SEGMENT BERDASARKAN MOTOR IMAGERY SEBAGAI PERINTAH KENDALI FES".

[12] E. Kurniadi, "PENERAPAN PEMBELAJARAN ELEKTRONIKA I BERBASIS KONFLIK KOGNITIF MELALUI METODE PERCOBAAN, DEMONSTRASI, CERAMAH, DAN DISKUSI.”

[13] P. M. Balqis, "LAPORAN MAGANG INDUSTRI PT. PANASONIC GOBEL LIFE SOLUTIONS MANUFACTURING INDONESIA." 